\title{
Buckling of very slender metal silos under eccentric discharge
}

\author{
Adam J. SADOWSKI, J. Michael ROTTER \\ University of Edinburgh, Scotland, UK \\ a.j.sadowski@ed.ac.uk
}

\begin{abstract}
Metal silos used to store granular solids often take the form of a cylindrical shell with an aspect ratio in the range $2<H / D<6$. It has long been recognised that the most serious load case for all silos is probably the condition of eccentric discharge of its stored solid, but in circular metal silos this is especially true. More failures have occurred under this condition than any other. This high failure rate is chiefly due to the complexity of the pressures exerted by an eccentrically discharging granular material, and the difficulty in understanding the pattern of stresses that develops in a shell wall under such unsymmetrical pressure regimes. The nonsymmetric behaviour of a shell structure under unsymmetrical pressures is not at all well described in the voluminous shell structures literature, and only a few studies have explored the mechanics leading to high local stresses which in turn lead to buckling failure under eccentric discharge.
\end{abstract}

This study follows an earlier initial exploration [26], in which buckling in a moderately slender perfect silo was explored. Here, the work is taken further to explore a very slender structure, and to investigate the imperfection sensitivity of this failure mode. The pressures caused by eccentric discharge are characterised using the new rules of the European Standard EN 1991-4 [5] that defines the Actions in Silos and Tanks. Using this new improved description of unsymmetrical eccentric discharge pressures, it is now possible to perform relatively realistic calculations relating to this common but complicated shell buckling condition. The calculations described here are part of a wider study believed to be the first of its kind and are 
Published in: Engineering Structures, 33(4), 1187-1194.

DOI: http://dx.doi.org/10.1016/j.engstruct.2010.12.040

undertaken using geometrically and materially nonlinear analyses in accordance with the European Standard EN 1993-1-6 [6] on Strength and Stability of Shells. The paper explores the structural behaviour of a slender silo under eccentric discharge, leading to buckling and including the critical effects of changes of geometry and imperfection sensitivity.

Keywords: Thin shell structures, solids flow, structural stability, nonlinear computer analysis, shell buckling, imperfection sensitivity, geometrically nonlinear. 
Published in: Engineering Structures, 33(4), 1187-1194.

DOI: http://dx.doi.org/10.1016/j.engstruct.2010.12.040

\section{Introduction}

It has long been recognised that the pressures on the walls of silos for the storage of granular solids change considerably from the state of filling and storing to the state of solids discharge. The latter case dominates silo design. But of all the potential patterns of pressure during discharge, the condition in which a channel of flowing solid develops against one part of the wall of a circular silo is by far the most demanding. This condition, termed eccentric discharge, has led to many serious and catastrophic failures and is most damaging of all in slender metal silos (a slender silo has an aspect ratio greater than 2 according to EN 1991-4 [8]). The failure mode in such slender thin-walled silos is buckling due to local axial compressive stresses, which are induced by unsymmetrical normal pressures against the wall.

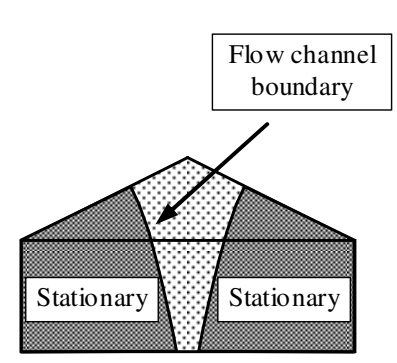

Retaining silo

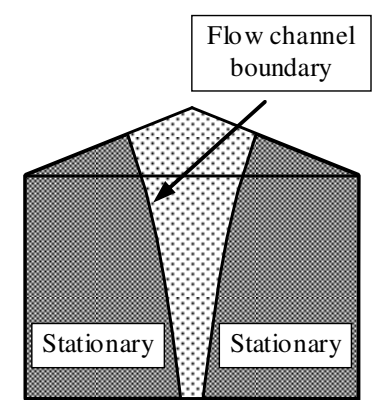

Squat silo

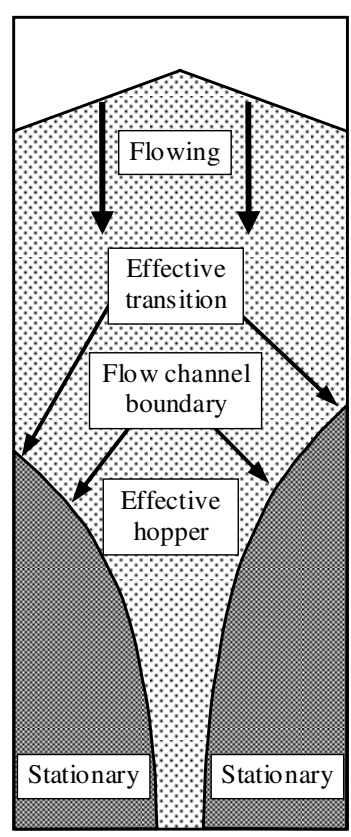

Slender silo

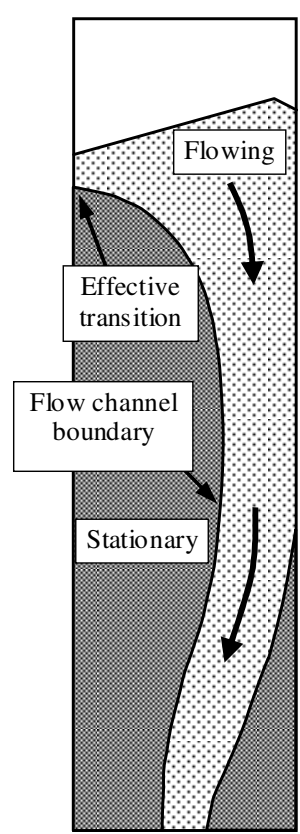

Very slender silo

Fig. 1 - Patterns of solids flow in silos of different aspect ratio (after EN 1991-4 [8])

In an earlier study [30], the phenomenon of buckling in a moderately slender perfect silo was explored. The basic mechanics were described, but it was not possible to determine how significant the effects of slenderness and imperfection sensitivity might be. Since these two aspects are particularly important in metal silos, they are 
Published in: Engineering Structures, 33(4), 1187-1194.

DOI: http://dx.doi.org/10.1016/j.engstruct.2010.12.040

the subject of this study. Further features of the problem, notably the question of what should be taken as failure, are also discussed. The significance of the category "very slender" is illustrated by the patterns of solids flow in silos shown in Fig. 1, which is taken from EN 1991-4 [8].

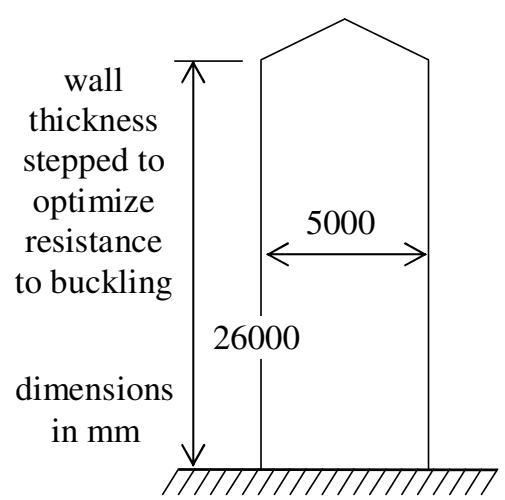

a) overall dimensions

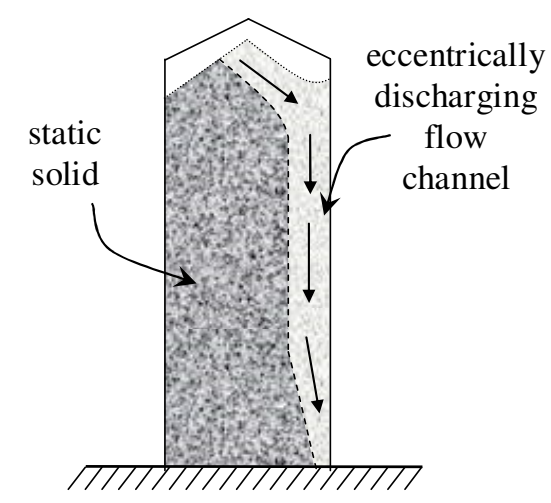

b) eccentric discharge flow channel

Fig. 2 - Illustration of eccentrically discharging flow channel and geometry of the example silo

When the silo is eccentrically discharged (see Figs 2 and 3), a very unsymmetrical pattern of normal pressures on the silo wall can arise, which leads to greatly increased local axial compressions that dramatically exacerbate the problem of buckling [20, 28]. A moderately realistic representation of the resulting pressure pattern is, for the first time, codified in the relatively recent European Standard EN 1991-4 [8]. The reader is invited to consult $[4,12,24,25]$ for background material on flow patterns and loadings in silos to illustrate the scope and load cases found in the EN 1991-4 [8] standard.

In this paper it is shown that failure under eccentric discharge is by buckling in the elastic range of material behaviour under local axial compressive membrane stresses induced by this highly unsymmetrical flow regime. This explanation is supported by the some research studies [22,24,25], but contradicts earlier work [14,20,35] and others. The latter authors' theories assume that a shell may be treated as a two- 
Published in: Engineering Structures, 33(4), 1187-1194.

DOI: http://dx.doi.org/10.1016/j.engstruct.2010.12.040

dimensional ring at each level, and consequently that failure is governed by yielding due to circumferential bending and tension. Such a treatment may be more realistic for thick-walled reinforced concrete silos. However, as was shown in [30] and will be expanded on further here, thin-walled metal silos behave very differently.

\section{Pressure patterns in silos}

The increased normal pressures that occur on a mass flow silo wall during concentric discharge fluctuate very erratically (see Fig. 3), and it is not yet possible to express them by simple equations $[17,18,22,28]$. Nonetheless, the increase in pressures is traditionally implemented in design through primitive overpressure factors which are based on early attempts at quantifying this phenomenon (e.g. [2,15]), though these attempts have not been successful at reproducing even the form of experimental silo pressure observations [28].

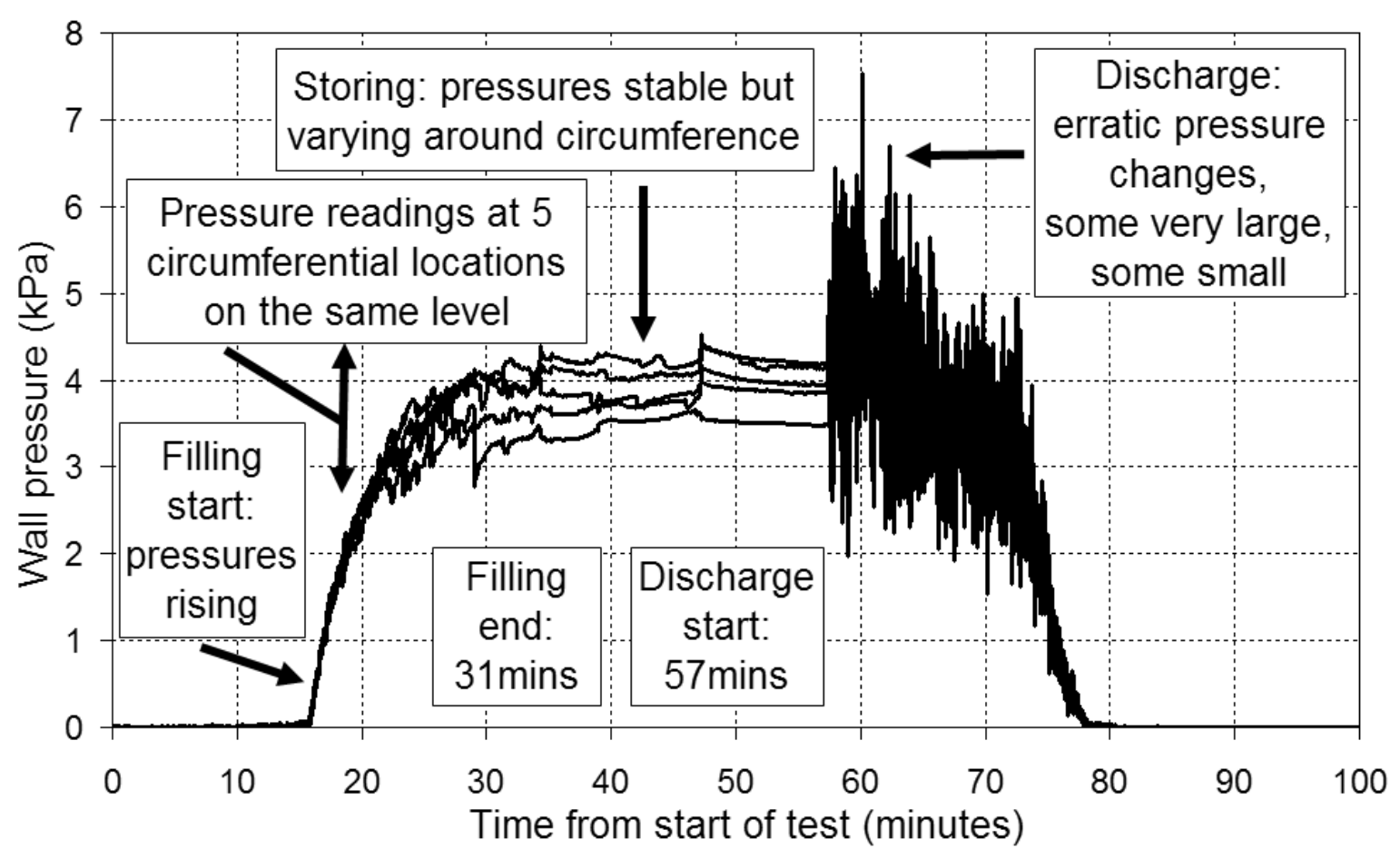

Fig. 3 - Example of measured erratic wall pressures during concentric discharge of a silo from five pressure cells at the same level but at different circumferential locations, after [28] 
Published in: Engineering Structures, 33(4), 1187-1194.

DOI: http://dx.doi.org/10.1016/j.engstruct.2010.12.040

In the first design standards which attempted to deal with this problem $[3,6,13]$, the effect of eccentricity of filling and discharge of solids was treated as an additional unsymmetrical component to the axisymmetric solid pressures. This treatment attempted to reproduce the structural consequences of asymmetrical loads on silos. A simple 'patch' of normal pressure with a prescribed magnitude, distribution and location was implemented in design. This approach, though rudimentary and hardly representative of a realistic pressure pattern, correctly identified unsymmetrical normal pressures rather than increased uniform pressures as being critical to early failure, though the implied expectation was that structural failure would be caused by circumferential bending.

Unfortunately, codified representations of patch loads differ considerably from one standard to another [30], mainly due to the lack of calibration using the pressures arising during eccentric discharge. The effect of patch loads has been found to be very detrimental in linear bifurcation analyses, but their effect on geometrically nonlinear bifurcation loads seems to be quite small $[31,32]$. Patch loads therefore cannot be relied upon to offer a conservative design process for eccentric discharge.

The recently published EN 1991-4 [8] defines three Action Assessment Classes which require different levels of sophistication in design, together with a range of properties for each stored material since different properties cause different aspects of the design to become critical. In the present study, as in the earlier study of [30], the unsymmetrical pressures caused by eccentric discharge are investigated using the rules of the relatively recent EN 1991-4 [8], based on a simplified version of the theory of Rotter [21,22]. This theory proposes a distribution for the pressures resulting from a parallel-sided circular flow channel forming against the wall, shown in Fig. 4. In the simplified EN 1991-4 [8] version, the solid exerts Janssen pressures outside the channel, elevated pressures at the edges and significantly decreased pressures within the flow channel. The relationship between the pressure drop and increase is chosen to retain the mean pressure at the Janssen filling value. This leads to a small global overturning moment on the silo inducing axial tension on the face 
Published in: Engineering Structures, 33(4), 1187-1194.

DOI: http://dx.doi.org/10.1016/j.engstruct.2010.12.040

adjacent to the flow channel. EN 1991-4 [8] requires this distribution to be used in the design of silos where eccentric discharge is expected and if the silo is in Action Assessment Class 2 or 3.

This simple model for the pressures associated with eccentric discharge is reasonably valid for solids that form steep-sided flow channels, which are packed more densely than the critical state, or with potential to develop cohesion [25,33]. In the previous study [30], the silo was designed to store wheat, which certainly does not flow in this manner, so the calculations presented there must be understood to relate to a densely packed solid that happens to have properties similar to those of wheat. In this paper, the stored solid is, instead, assumed to be cement, which is much more likely to develop a flow pattern in this form [16].

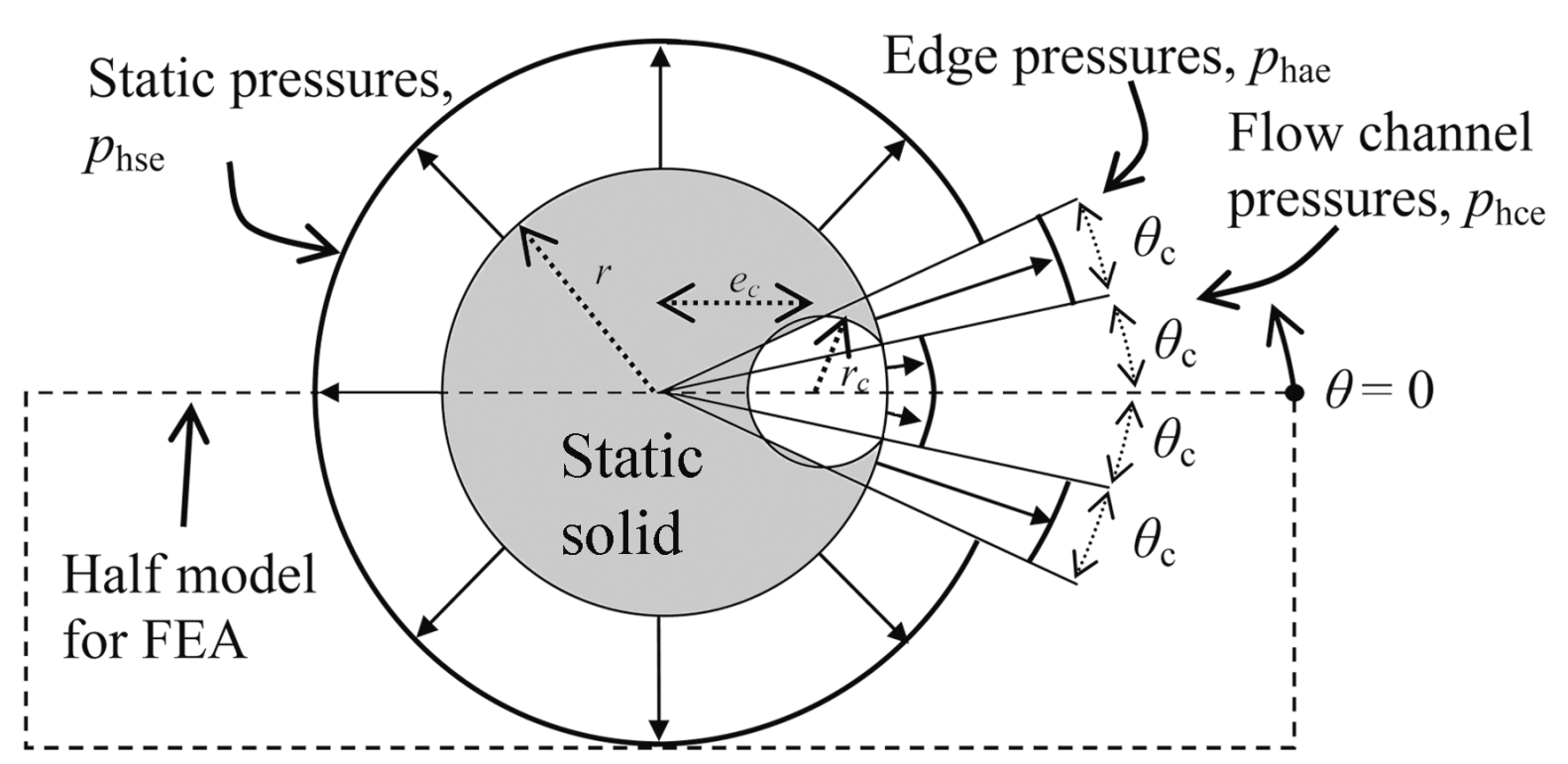

Fig. 4 - Circumferential cross-section of eccentric flow channel horizontal pressures, after EN 1991-4 [8]

\section{Design of an example steel silo for axisymmetric loading}

The goal of this paper is to explore the structural behaviour of a silo under eccentric discharge when it has not been designed for it. To this end, a design was produced for 
Published in: Engineering Structures, 33(4), 1187-1194.

DOI: http://dx.doi.org/10.1016/j.engstruct.2010.12.040

an example silo subjected to axisymmetric loads only, and its behaviour under unsymmetrical loads due to eccentric discharge was investigated with a finite element analysis. Accidental eccentric discharge may occur due to blockages, feeder malfunction, material segregation due to humidity or different packing densities, and many other causes [25].

A simple cylindrical steel silo with a vertical wall, flat bottom and conical shell roof (inclination $15^{\circ}$ to the horizontal) was designed for symmetrical loads only arising from the storage of 677 metric tons of cement with Class D2 wall friction ('smooth', with a mean wall friction coefficient of $\mu=0.46$ ). Structural design was done according to EN 1993-1-6 [9] hand calculations and included the strengthening effect of internal pressure on the buckling resistance, with properties for cement taken from EN 1991-4 Annex E [8] using the maximum friction case since the design against buckling is dominant. In all cases the loading consists of internal pressure $\left(p_{\mathrm{n}}\right)$ and frictional tractions $\left(p_{\mathrm{f}}\right)$ only: there is no further axial loading beyond that caused by friction between the granular solid and the silo wall $\left(p_{\mathrm{f}}=\mu p_{\mathrm{n}}\right)$.

The cylinder wall height was $26 \mathrm{~m}$ and the radius $2.5 \mathrm{~m}$, giving an aspect ratio of 5.2 , which places it far into the class of 'Slender' and corresponds to a very slender design. Action Assessment Class 2 was assumed based on the storage capacity. The requirement for a small unsymmetrical patch load on the silo, which has little effect on a design of this kind, was ignored to keep the design as simple as possible for future interpretation. Discharge factors for normal pressures $\left(C_{\mathrm{h}}\right)$ and frictional tractions $\left(C_{\mathrm{w}}\right)$ were taken as 1.15 and 1.1 respectively. The partial safety factors for unfavourable actions $\left(\gamma_{\mathrm{F}}\right)$ and for stability $\left(\gamma_{\mathrm{M} 1}\right)$ where taken as 1.5 and 1.1 respectively, separating the characteristic values by a factor of $1.5 \times 1.1=1.65(\mathrm{EN}$ 1993-4-1 [10]). This safety factor provides a valuable reference against which nonlinear computational analyses may be assessed.

As in all normal engineering practice for silo design, the wall thickness was varied in a stepwise manner from $3 \mathrm{~mm}$ at the top to $9 \mathrm{~mm}$ at the base. This made the wall just 
Published in: Engineering Structures, 33(4), 1187-1194.

DOI: http://dx.doi.org/10.1016/j.engstruct.2010.12.040

thick enough at the base of each strake and at the silo base. To ensure that the design was just critical at the base of each strake, the strakes were permitted to have any length and were not constrained by practical steel sheet widths. The design axial membrane stress resultants and design resistances are shown in Fig. 5. A membrane stress resultant is calculated as the product of the local stress and the local thickness values, and thus shows a continuous line down the meridian of the silo. The corresponding design thicknesses for buckling are shown in Fig. 6 (evaluated in a point-wise manner irregardless of the finite size of true buckles, as required by the hand-design procedure of EN 1993-1-6 [9]), together with the much smaller design thicknesses required to withstand simple bursting failure alone. A similar design procedure, though for a silo of a lower aspect ratio which additionally included a uniform wall thickness design, was used in the previous study [30].

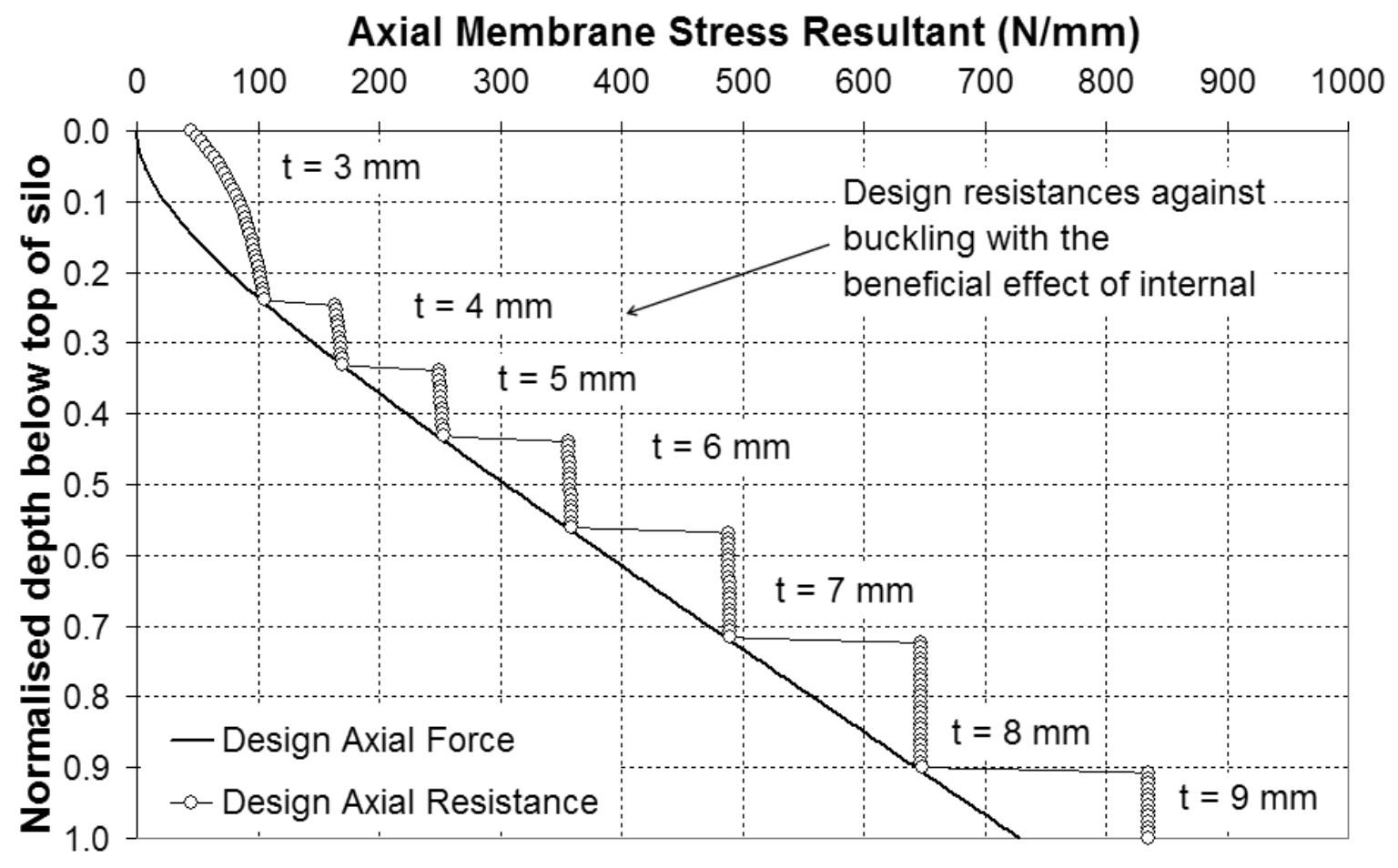

Fig. 5 - Distribution of design axial membrane stress resultants 
Published in: Engineering Structures, 33(4), 1187-1194.

DOI: http://dx.doi.org/10.1016/j.engstruct.2010.12.040

\section{Wall thickness $(\mathrm{mm})$}

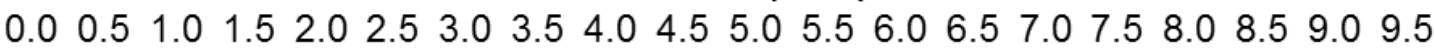

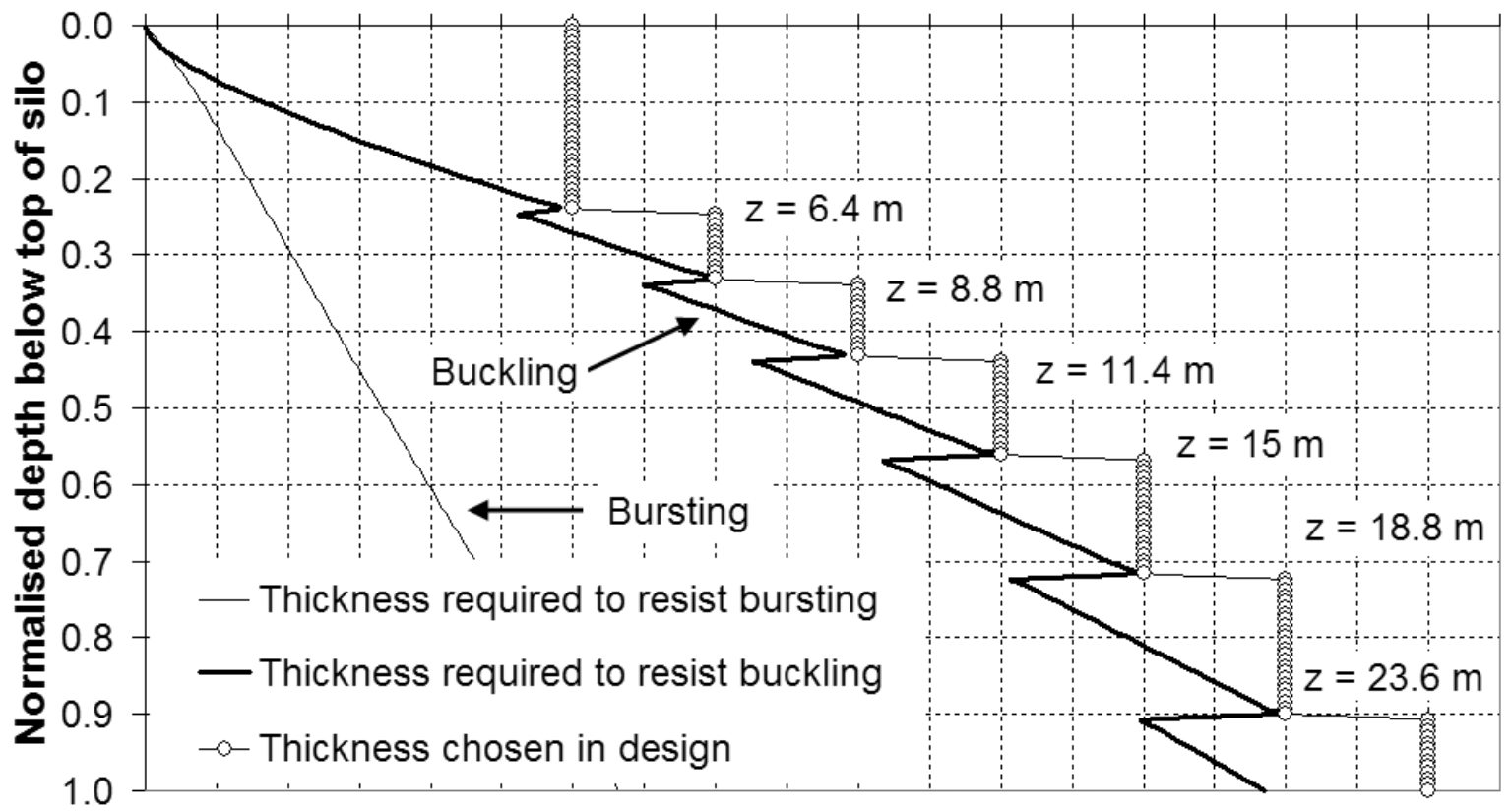

Fig. 6 - Distribution of design thicknesses to resist bursting and buckling

The buckling strength assessment according to EN 1993-1-6 [8] requires that the quality of expected construction is considered at the design stage. A Fabrication Tolerance Quality Class of C (i.e. 'normal') was assumed, corresponding to a more imperfect wall which was therefore thicker. The shell material was assumed to be isotropic steel with an elastic modulus of $200 \mathrm{GPa}$, a Poisson's ratio of 0.3 and a yield stress of $250 \mathrm{MPa}$. The reader may consult $[7,26]$ for in-depth background material on the EN 1993-1-6 [9] standard.

\section{Numerical analysis of the example silo}

The aim of this study is to explore the behaviour of the example silo under both concentric and eccentric discharge. For such comparisons, it is necessary to perform different types of computational analysis with the different load cases. The silo was therefore first analysed under the symmetrical design loads and then under eccentric discharge using the commercial finite-element package ABAQUS [1]. The wall was 
Published in: Engineering Structures, 33(4), 1187-1194.

DOI: http://dx.doi.org/10.1016/j.engstruct.2010.12.040

assumed to have a pinned base, whilst the conical roof gave a realistic restraint of outof-round displacements, which is important when analysing silos under unsymmetrical loads [5,23]. Using symmetry, only half of the silo was modelled with powerful but computationally expensive nine-node reduced-integration S9R5 elements. In addition to being able to accurately predict the correct buckling load and mode, a half-structure model is more computationally efficient than a whole-structure model [34]. It was also verified that a whole-structure model produced buckling modes that were symmetric relative to the plane of symmetry through the structure under both concentric and eccentric discharge loads (Fig. 4).

The roof was modelled with four-node reduced integration S4R5 elements in order to save on computation time. The small error arising from the $\mathrm{C} 0$ discontinuity between the S4R5 and S9R5 elements (which shared all nodes at the eaves) was confined to a very local zone, and did not affect any of the outcomes or stress patterns reported here. This was additionally verified by calculations that used S9R5 elements throughout the model. Within the cylinder of the silo, the internal pressure and frictional traction loads were applied as normal pressure and surface traction components on each S9R5 element. The S4R5 elements of the roof were not loaded directly. The mesh resolution was carefully increased near changes of wall thickness, local imperfections, the entire flow channel and in regions where buckles were expected to form. An ideal elastic-plastic material law was assumed. The geometrically nonlinear load-deflection paths were followed using the modified Riks procedure which uses full arc length control [19] and its implementation in ABAQUS [1] retains the strain history at the end of each load increment to capture the full path dependency of the outcome when plasticity is involved. The internal pressure and frictional traction loadings were proportionately scaled in the Riks procedure.

Local axisymmetric imperfections representing weld depressions in the form Type A defined by Rotter and Teng [29] were introduced at all changes of plate thickness and at selected intervals between them. The depression amplitude was chosen as identical, in each strake, to the value adopted in the hand calculation design process 
Published in: Engineering Structures, 33(4), 1187-1194.

DOI: http://dx.doi.org/10.1016/j.engstruct.2010.12.040

according to EN 1993-1-6 [9]. This choice was made to produce a silo corresponding to typical commercial practice and to retain consistency between the design and the computational calculations.

The full suite of computational shell buckling calculations were performed according to EN 1993-1-6 [9]: LA - Linear elastic Analysis to find the reference stresses; LBA - Linear Bifurcation Analysis to find the lowest linear buckling eigenvalue and eigenmode; MNA - Materially Nonlinear Analysis to find the reference plastic collapse load; GNA/GMNA - Geometrically Nonlinear Analysis without/with material plasticity to find the lowest bifurcation load and mode; and GNIA/GMNIA Geometrically Nonlinear Analysis with Imperfections without/with material plasticity to find the lowest bifurcation load and mode for the imperfect structure. A similar program of calculations was used in [30], since it is clear that this comprehensive set gives the fullest insight into the behaviour of any complex structural system under static loads.

\section{Results and discussion}

\subsection{Behaviour of the example silo under symmetrical discharge pressures}

The very slender silo was first analysed under symmetrical loading with the characteristic values of the discharge pressures and frictional tractions assumed in the design calculations. It is known that many conservative assumptions are incorporated into the hand design process according to which the silo was designed, so the safety factor of 1.65 assumed in design was expected to be exceeded when the silo was analysed using a GMNIA analysis. The load proportionality factors at failure were evaluated for each analysis type. These are analogous to the product of the partial safety factors adopted in limit state [10] or LFRD design. A summary of the load factors achieved under concentric discharge is given in Table 1. The corresponding buckling modes are shown in Fig. 7 while the nonlinear load-axial displacement paths are presented in Fig. 8. 
Published in: Engineering Structures, 33(4), 1187-1194.

DOI: http://dx.doi.org/10.1016/j.engstruct.2010.12.040

Table 1 - Summary of load factors for the example silo under concentric discharge

\begin{tabular}{|c|c|c|c|c|c|c|}
\hline $\begin{array}{c}\text { Concentric discharge load } \\
\text { proportionality factors }\end{array}$ & LBA & MNA & GNA & GMNA & GNIA & GMNIA \\
\cline { 2 - 7 } & 7.65 & 4.54 & 7.31 & 3.85 & 3.41 & 2.83 \\
\hline
\end{tabular}

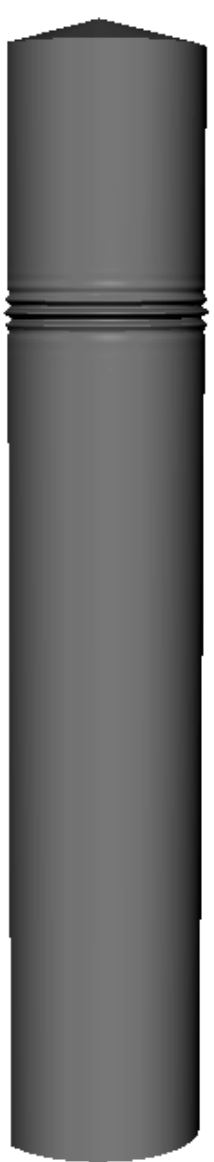

LBA

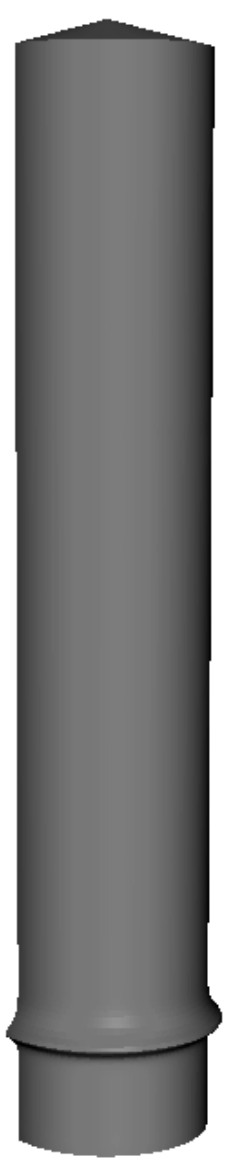

MNA

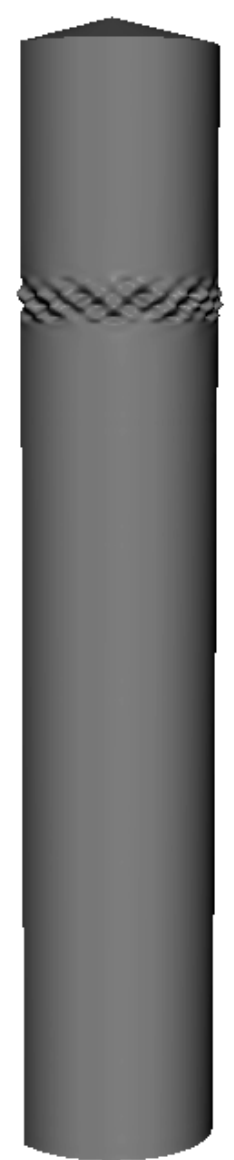

GNA

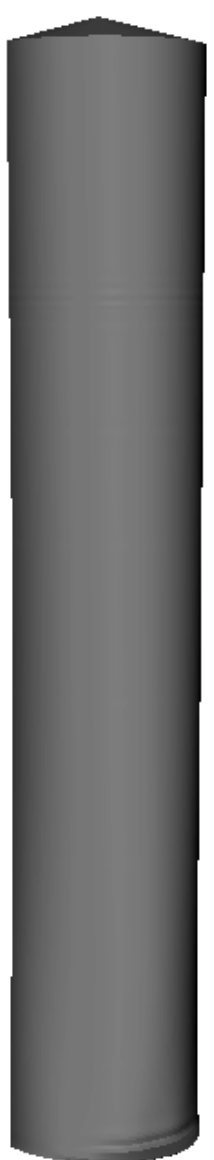

GMNA

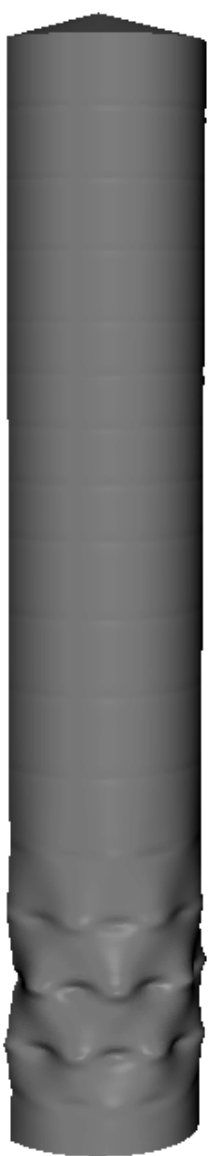

GNIA

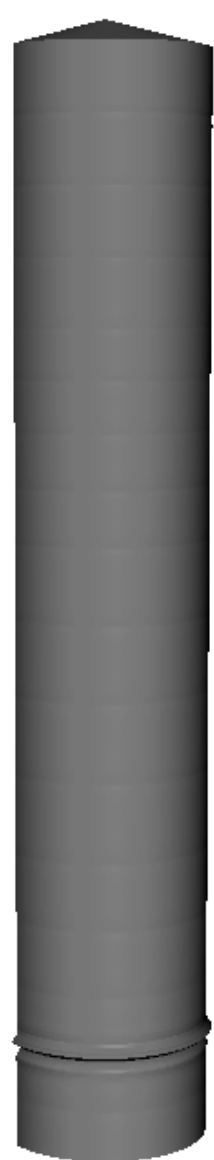

GMNIA

Fig. 7 - Incremental buckling modes (except for LBA and MNA) under concentric discharge

The critical location for buckling failure under axisymmetric loading is always at the base of a strake, since the axial compression increases monotonically from top to bottom (Fig. 5). In this case the critical zones are either the bottom of the thinnest $3 \mathrm{~mm}$ or $8 \mathrm{~mm}$ strakes, although because all strakes were designed to be equally critical, there is little to choose between them in determining which will be just the most critical. The high values for the LBA and MNA load factors suggest that 
Published in: Engineering Structures, 33(4), 1187-1194.

DOI: http://dx.doi.org/10.1016/j.engstruct.2010.12.040

stability and plasticity will interact, which is then reflected in the large drop in load factor from GNA to GMNA and the development of the elastic-plastic elephant's foot buckling mode at the base of the silo. Additionally, the GNA load factor is very close to the LBA load factor (and the load-deflection paths overlap, see Fig. 8) which shows that the pre-buckling behaviour is very close to linear. The introduction of a circumferential weld depression imperfection of the design amplitude is detrimental to the silo strength, and the GMNIA mode reflects the MNA plastic collapse mechanism. A similar behaviour was found for the much less slender silo in the previous study [30], so the present study confirms this behaviour as characteristic for a wider range of geometries.

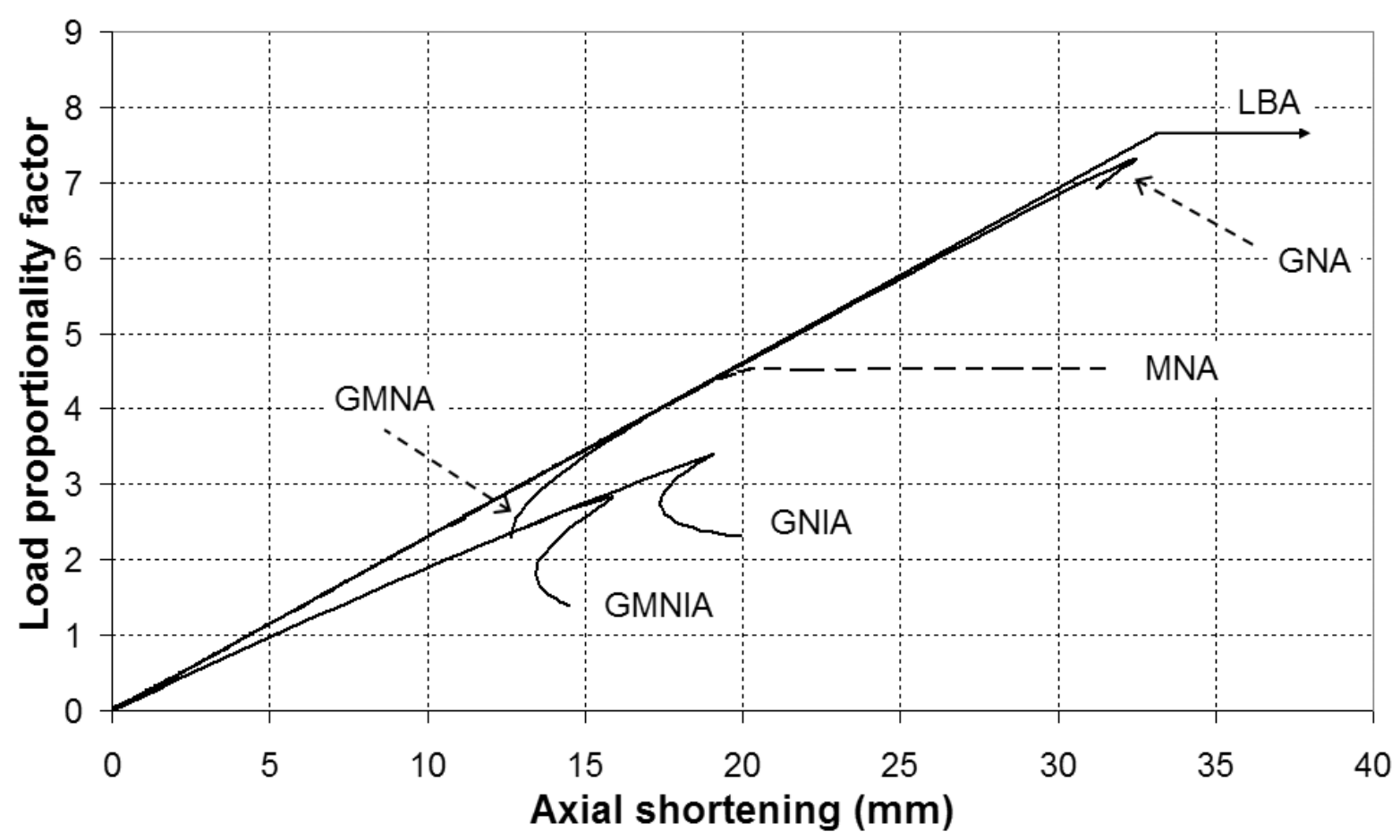

Fig. 8 - Nonlinear load-axial displacement paths under concentric discharge

The lowest GMNIA factor of 2.83 is $72 \%$ larger than the hand calculation value of 1.65. Since the axisymmetric weld depression is probably the most damaging practical form [26], the assumptions in the hand design process for symmetric loads are quite conservative, both for the elastic stability and plastic collapse calculations. 
Published in: Engineering Structures, 33(4), 1187-1194.

DOI: http://dx.doi.org/10.1016/j.engstruct.2010.12.040

The nonlinear load-displacement paths are very typical for shells under axisymmetric loading. The node whose displacement is shown is at the top of the silo. The introduction of axisymmetric weld imperfections reduces the stiffness markedly and also causes earlier failure. The more sophisticated analyses produce lower load factors, so both geometric and material nonlinearity must be considered in silo design under symmetrical loads.

\subsection{Behaviour of the example silo under eccentric discharge pressures}

The main aim of this paper is to explore the structural behaviour and imperfection sensitivity of a very slender silo under an (accidental) eccentric discharge event. Such discharge conditions often precipitate silo failures, when either a feeder malfunctions, an outlet intended for final cleanout is opened when the silo is full, a new discharge device is fitted without proper testing and other similar conditions (see EN 1991-4 [8]). Thus the following calculations give a good insight into many silo disasters. Here, the eccentric discharge flow channel size $\left(r_{\mathrm{c}}\right)$ is taken as 0.6 times the silo radius (see Fig. 4), as it was believed to be about the most detrimental size.

Under the unsymmetrical pressures defined by EN 1991-4 for very eccentric discharge (Fig. 4), high axial compressive membrane stresses develop close to the midheight of the silo down the centre of the flow channel [22,24] as a direct consequence of the unsymmetrical pattern of normal pressures [11]. By contrast, high axial tensile stresses develop at the edges of the flow channel, with compressive values at the base. Clearly, either of the two regions of high compressive stress may become critical for buckling failures, depending on the axial variation of plate thicknesses and internal pressure. This stress distribution, first identified by Rotter [22], is shown in Fig. 9 for the GNA/GMNA analysis at the instant before bifurcation. 
Published in: Engineering Structures, 33(4), 1187-1194.

DOI: http://dx.doi.org/10.1016/j.engstruct.2010.12.040

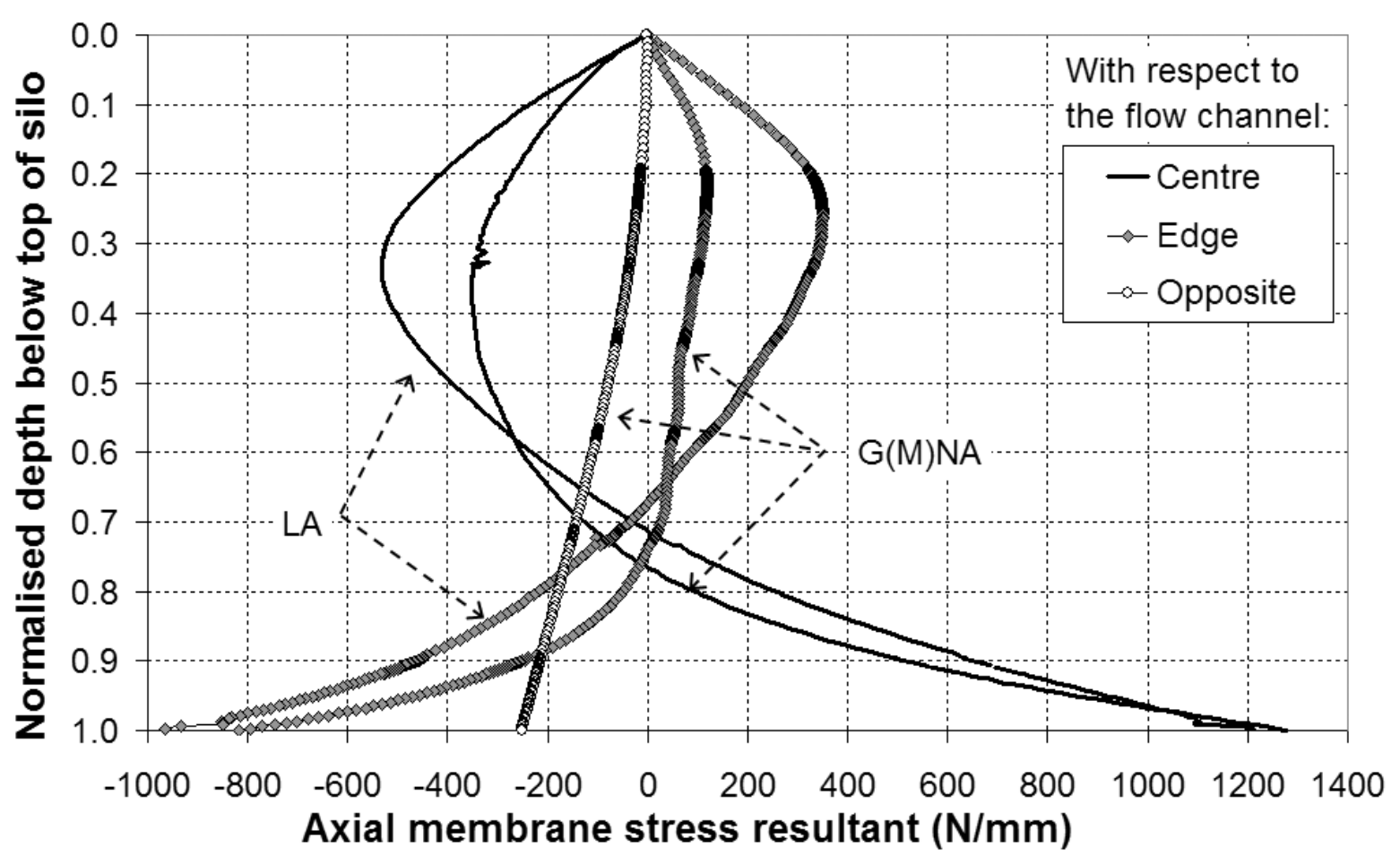

Fig. 9 - Axial membrane stress distribution (at instant of bifurcation) under eccentric discharge analysed with GNA/GMNA and LA (factored with LBA)

The largest compressive stresses are at the base of the silo wall at the edge of the flow channel, and if the wall thickness had been uniform throughout the silo, this location would be critical and susceptible to local elastic-plastic buckling failure (as seen in [30]). However, since high compressive stresses also develop at midheight at the centre of the flow channel, this location becomes critical because the local wall thickness is less, as is always the case in practice. On the far side of the silo from the channel, the axial membrane stress resultant is almost unaffected, and closely corresponds to the axisymmetric loading case, demonstrating that the global moment applied to the silo by the adopted pressure pattern is not significant.

A summary of the load factors at failure for the example silo under eccentric discharge is presented in Table 2. The incremental buckling modes are shown in Fig. 10, while the nonlinear axial displacement paths are presented in Fig. 11. The axial 
Published in: Engineering Structures, 33(4), 1187-1194.

DOI: http://dx.doi.org/10.1016/j.engstruct.2010.12.040

displacement is shown for a point at the top of the silo at the centre of the flow channel.

Table 2 - Summary of load factors for the example silo under eccentric discharge

\begin{tabular}{|c|c|c|c|c|c|c|}
\hline $\begin{array}{c}\text { Eccentric discharge load } \\
\text { proportionality factors }\end{array}$ & LBA & MNA & GNA & GMNA & GNIA & GMNIA \\
\cline { 2 - 7 } & 0.21 & 0.65 & 0.37 & 0.37 & 0.22 & 0.20 \\
\hline
\end{tabular}

All the load factors in Table 2 are very far below the concentric discharge values. This illustrates the very damaging effect of unsymmetrical pressures on cylindrical shells. The design, which was so conservative under concentric discharge, is very far from safe under eccentric discharge. The MNA factor, relating to a plastic collapse mechanism in circumferential bending, is higher than all the others and does not contribute to the behaviour at all. This is an important observation for those who have believed that the failure mechanism was yield under circumferential bending $[14,20,35]$.

It is surprising to find that the GNA factor is almost double the LBA factor, suggesting that large deformations change the geometry considerably and result in significant strength gains. Figure 9 additionally shows the reference LA values (at the LBA factor), which are much greater than the GNA pre-buckling stresses. This phenomenon, by which a flattening of the shell wall by an unsymmetrical pressure pattern leads to reduced axial compressive stresses, is a rather unexpected finding. The flattening of the wall causes a locally increased radius-to-thickness ratio. It had been commonly supposed in the past (e.g. [21]) that a further reduction might have to be included in the buckling strength evaluation. Evidently, this concept was wrong. It illustrates the need for many further studies of cylindrical shells under unsymmetrical loads to achieve a fuller understanding of the mechanics of the behaviour. 
Published in: Engineering Structures, 33(4), 1187-1194.

DOI: http://dx.doi.org/10.1016/j.engstruct.2010.12.040
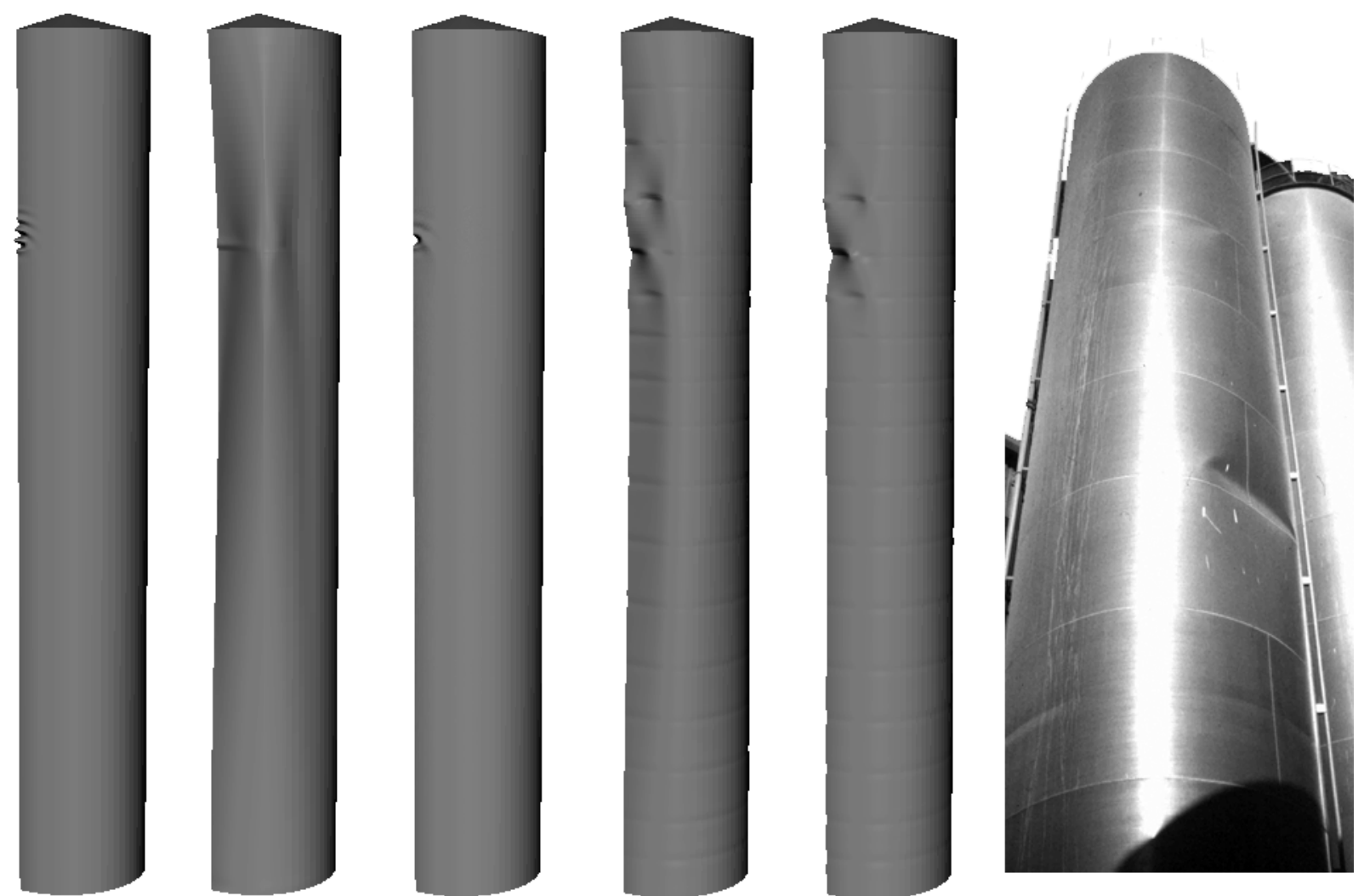

LBA MNA

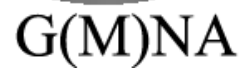

GNIA

GMNIA In-service buckle

Fig. 10 - Incremental buckling modes (except for LBA and MNA) under eccentric discharge, including an example of an actual buckle of a silo in service (J.M. Rotter)

The buckling modes in Fig. 10 show that buckles occur exclusively at midheight. Additionally, the identical values for the load factors of the GNA and GMNA analyses, and the closeness of the load factors for the GNIA and GMNIA analyses, show that the buckling is almost entirely elastic, whether the silo is perfect or imperfect. This failure mode relates well to known failures in service, as illustrated in the same figure.

The load-displacement paths of Fig. 11 show that the structure exhibits significant stiffening behaviour under geometric nonlinearity (the GNA/GMNA paths) when a significant change of shape occurs due to the local circumferential inward bending at the flow channel. There is a sharp bifurcation peak followed by a reversal in the loading path, typical of highly imperfection-sensitive unstable post-buckling 
Published in: Engineering Structures, 33(4), 1187-1194.

DOI: http://dx.doi.org/10.1016/j.engstruct.2010.12.040

behaviour [36]. With imperfections included, the GNIA and GMNIA paths show a clear point of inflection at a load factor of approximately 0.22 , followed by indefinite geometric hardening with a progressive growth of the imperfection mode. With no negative eigenvalues reported at the change of slope, it is evident that a smooth transition has been made from the pre-buckling to the stable post-buckling mode.

This phenomenon often occurs when imperfection amplitudes are large and result in a blurring of the buckling behaviour [27,36], illustrated further on the imperfection sensitivity curve in Fig. 12. As the imperfection amplitude is increased, the bifurcation point progressively disappears and turns into a point of inflection on the load-displacement path, a phenomenon that is shown clearly in Fig. 13. This figure also shows that smaller imperfection amplitudes lead to bifurcation points at lower load factors and raises the vital problem for computational analysts to decide what criterion of failure should be used when the transition from pre- to post-buckling is smooth. The plot shown in Fig. 12 follows the style of Yamaki [36] in indicating inflection points when no bifurcation occurs, but it poses a significant problem for the re-drafting of EN 1993-1-6 [9] because the analyst exploiting GMNIA calculations cannot be expected to generate an entire imperfection sensitivity curve to identify this condition when only trying to design one structure. The standard currently specifies large amplitude imperfections in the expectation that this will lead to low strength evaluations, and although it requires the analyst to check that lower amplitudes do not reduce the strength, the condition of a smooth transition such as that seen here is not really taken into account. 
Published in: Engineering Structures, 33(4), 1187-1194.

DOI: http://dx.doi.org/10.1016/j.engstruct.2010.12.040

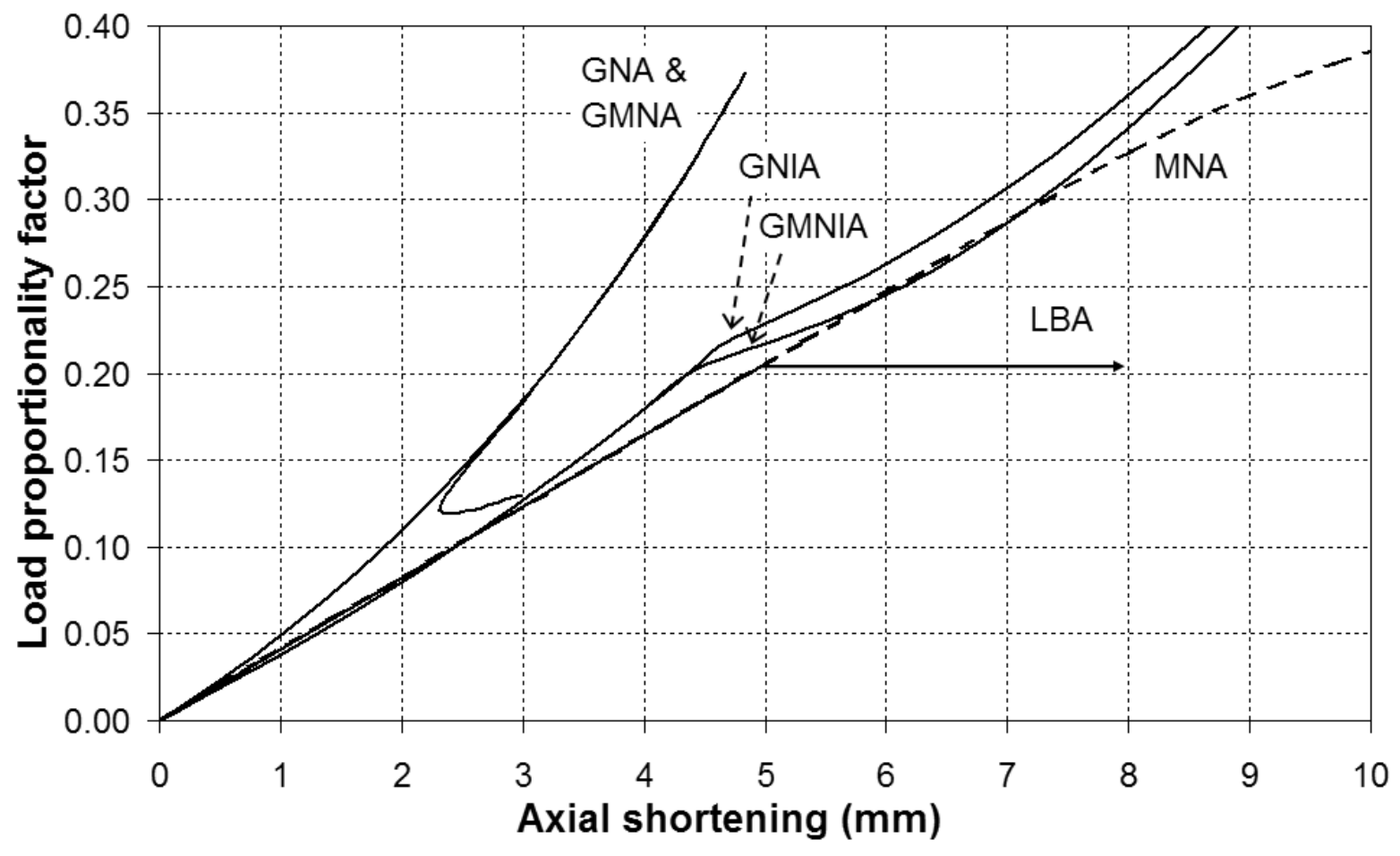

Fig. 11 - Nonlinear load-axial displacement paths under eccentric discharge

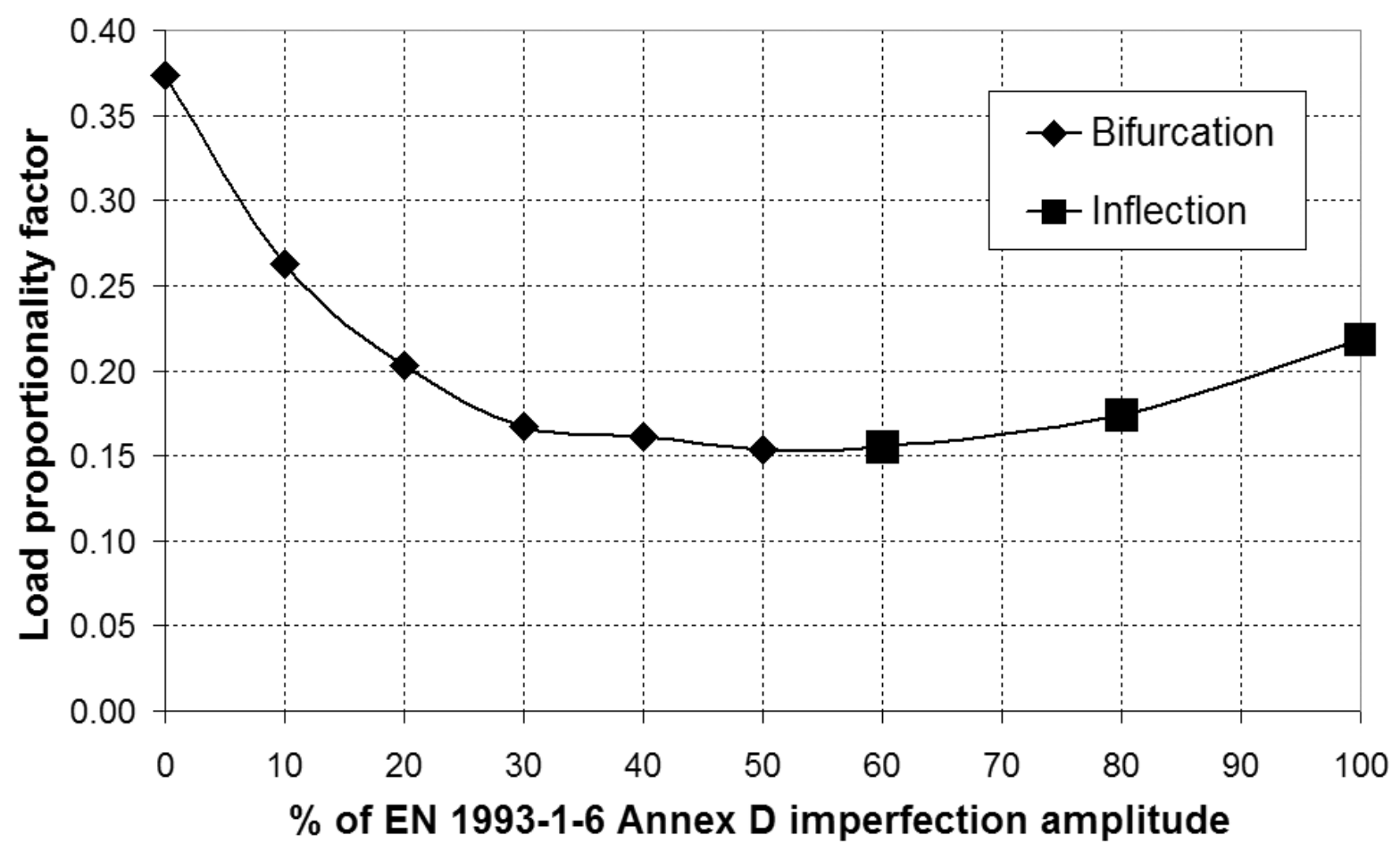

Fig. 12 - GNA imperfection sensitivity curve 
Published in: Engineering Structures, 33(4), 1187-1194.

DOI: http://dx.doi.org/10.1016/j.engstruct.2010.12.040

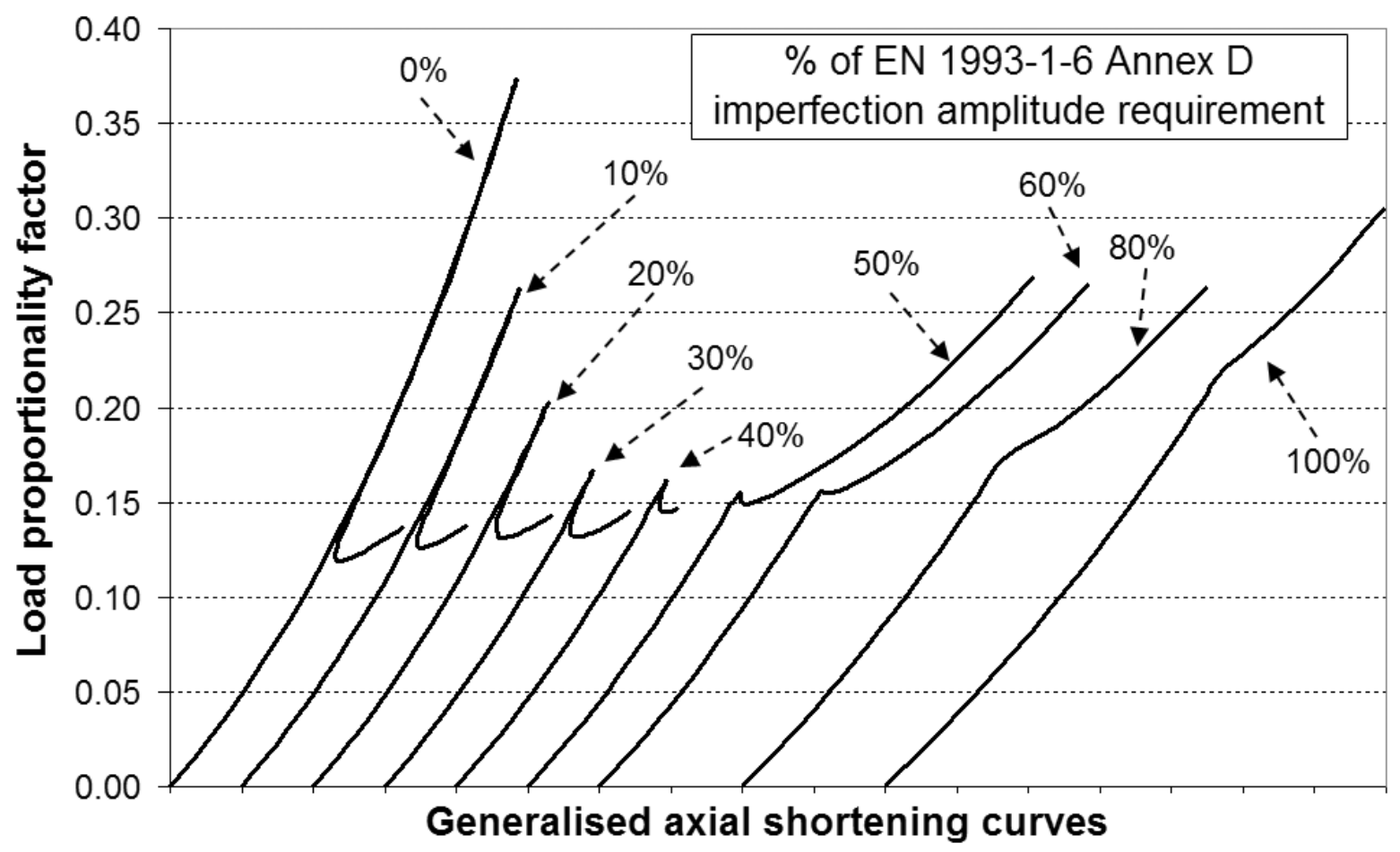

Fig. 13 - Nonlinear load-axial displacement paths for the GNA imperfection sensitivity curve

\section{Conclusions}

The following conclusions may be drawn, based on the results of this study:

1. For stepped-wall silos under axisymmetric loading conditions, nonlinear finite element computations have shown that the provisions of the EN 1993-1-6 [8] shell structures standard for direct (hand) design are very conservative for both stability and plastic collapse calculations.

2. The eccentric discharge pressure model of the relatively recent EN 1991-4 standard is highly damaging to a realistic very slender stepped-wall thinwalled metal silo which has not been explicitly designed for eccentric discharge. This pressure pattern completely overcomes the reserve of strength that the silo had under concentric discharge and provokes a very early elastic buckling failure. The cause of this early failure is the development of very high axial compressive membrane stresses down much of the silo wall near the centre of the flow channel, with its peak at approximately midheight. 
Published in: Engineering Structures, 33(4), 1187-1194.

DOI: http://dx.doi.org/10.1016/j.engstruct.2010.12.040

3. The imperfection sensitivity of a very slender thin-walled metal silo under eccentric discharge is highly complex and counter-intuitive. At small imperfection amplitudes, dramatic bifurcation buckling occurs. But larger amplitudes may completely remove the bifurcation point, turning it into a point of inflection on the smooth path from pre-buckling to post-buckling. This provokes the vital question for all computational analysts of imperfect shells: what criterion of failure should be used in structures with such a pattern of behaviour?

4. The lowest GMNIA buckling load factor may well occur at imperfection amplitudes much lower than those prescribed by EN 1993-1-6 and, although it is required by EN 1993-1-6, it is very onerous for the shell analyst to be required to seek out the lowest point on the imperfection sensitivity curve for every designed structure.

5. It has been found that the silo wall undergoes significant local flattening when subjected to the unsymmetrical pressures associated with the EN 1991-4 eccentric discharge condition. Furthermore, this flattening actually leads to reduced axial compressive stresses and thus an increased nonlinear buckling strength when compared to the linear buckling strength value. Consequently, flattening of the silo wall should not be included in the buckling strength evaluation as it cannot be guaranteed that the resulting assessment will be conservative under all load cases. Further research is needed to understand the mechanics of this behaviour.

The provisions of the EN 1993-1-6 standard for nonlinear computational analyses of imperfect shells should be re-drafted. It is clear that they were formulated by considering the experimental database, which is dominated by axisymmetric loading. When these provisions are applied to shells under non-symmetric loading that leads to complex behaviour, the interpretation of the calculations for design purposes may be quite difficult. 
Published in: Engineering Structures, 33(4), 1187-1194.

DOI: http://dx.doi.org/10.1016/j.engstruct.2010.12.040

\section{References}

[1] ABAQUS. ABAQUS Version 6.9 Documentation. Dassault Systèmes Simulia Corp., Providence, RI, USA. 2009.

[2] Arnold P.C., McLean A.G. and Roberts A. W., Bulk Solids: Storage, Flow and Handling. TUNRA Bulk Solids Handling Research Associates, University of Newcastle, Australia, 1978, $2^{\text {nd }}$ edition 1980.

[3] AS 3774., Loads on bulk solids containers. Sydney: Standards Australia, 1996.

[4] Blight G., Assessing Loads on Silos and Other Bulk Storage Structures Research Applied to Practice. Taylor and Francis, New York, 2006.

[5] Calladine C.R., Theory of Shell Structures. Cambridge University Press, 1983.

[6] DIN 1055-6., Design loads for buildings: loads in silo bins. Deutsches Institut für Normung, Berlin, Germany, 1987.

[7] ECCS, Buckling of Steel Shells - European Design Recommendations, European Convention for Constructional Steelwork, Brussels, 5th Edition, 2008.

[8] EN 1991-4., Eurocode 1: Basis of Design and Actions on Structures, Part 4 Silos and Tanks. CEN, Brussels, 2006.

[9] EN 1993-1-6., Eurocode 3: Design of Steel Structures, Part 1.6 - Strength and Stability of Shell Structures. CEN, Brussels, 2007.

[10] EN 1993-4-1., Eurocode 3: Design of Steel Structures, Paart 4.1 - Silos. CEN, Brussels, 2007.

[11] Gould P.L., Cylindrical Shell Slice-Beam. J. of Eng. Mech., ASCE, 1988, 114 (5), 905-911.

[12] Hampe E., Silos, Band 1 - Grundlagen (In German). VEB Verlag für Bauwerke, Berlin, 1987.

[13] ISO 11697, Basis for design of structures - loads due to bulk materials. International Standard, 1995.

[14] Jenike A.W., Denting of Circular Bins with Eccentric Drawpoints. J. of the Struct. Div., ASCE, 1967; 93 (ST1); 27-35. 
Published in: Engineering Structures, 33(4), 1187-1194.

DOI: http://dx.doi.org/10.1016/j.engstruct.2010.12.040

[15] Jenike A.W., Johanson J.R. and Carson J.W., Bin Loads - Parts 2, 3 and 4: Concepts, Mass Flow Bins, Funnel Flow Bins. J. of Eng. for Industry, Trans. ASME, 1973, Vol. 95, Series B, N. 1, pp 1-5, 6-12, 13-16.

[16] Kaldenhoff M., Full Scale Experiences with Flow Funnel. Proc. 50th Anniversary Conference of the International Association for Shell and Spatial Structures, 2009, Valencia, Spain, pp. 77-89.

[17] Nielsen J., Pressures from flowing granular solids in silos. Phil. Trans. Royal Society of London: Philosophical Transactions: Mathematical, Physical and Engineering Sciences, 1998, Series A, 356, 2667-2684.

[18] Ooi J.Y., Pham L. and Rotter J.M., Systematic and random features of measured pressures on full-scale silos. Engineering Structures, 1990, Vol. 12, N. 2, 74-87.

[19] Riks E., An incremental approach to the solution of snapping and buckling problems. Int. J. of Solids and Structures, 1979, Vol. 15, 529-551.

[20] Roberts A.W. and Ooms M., Wall Loads in Large Metal and Concrete Silos and Silos due to Eccentric Draw-Down and other Factors. Proc. of the $2^{\text {nd }}$ Int. Conf. on Design of Silos for Strength and Flow, Stratford-upon-Avon, 1983, 151-170.

[21] Rotter J.M., Stability Problems in Cylindrical Bins under Axial Compression. Proc. of the Joint US/Australian Workshop on the Loading, Analysis and Stability of Thin Shell Bins, Tanks and Silos, University of Sydney, 1985, 106117.

[22] Rotter J.M., The analysis of steel bins subject to eccentric discharge. Proc. of the $2^{\text {nd }}$ International Conference on Bulk Materials Storage, Handling and Transportation, IEAustralia, Wollongong, 264-171, 1986.

[23] Rotter J.M., Bending Theory of Shells for Bins and Silos. Trans. of Mech. Eng., IE Aust, 1987, ME12 (3), 264-271.

[24] Rotter J.M., Pressures, Stresses and Buckling in Metal Silos containing Eccentrically Discharging Solids, in Festschrift Richard Greiner, Celebration volume for the $60^{\text {th }}$ birthday of Prof. Richard Greiner, TU Graz, Austria, 2001, 85-104. 
Published in: Engineering Structures, 33(4), 1187-1194.

DOI: http://dx.doi.org/10.1016/j.engstruct.2010.12.040

[25] Rotter J.M., Guide for the Economic Design of Circular Metal Silos. Spon Press, 2001.

[26] Rotter J.M., Buckling of cylindrical shells under axial compression. Chapters 1 \& 2 of Buckling of Thin Metal Shells, eds J.G. Teng \& J.M. Rotter, Spon, London, 2004, 1-87.

[27] Rotter J.M., A framework for exploiting different computational assessments in structural design. Proc. $6^{\text {th }}$ Int. Conf. on Steel and Aluminum Structrues, $6^{\text {th }}$ ICSAS 07, Oxford, June 2007.

[28] Rotter J.M., Silo and hopper design for strength. Chapter 4 of Bulk Solids Handling Equipment Selection and Operation, ed D. McGlinchey, Blackwell, Oxford, 2007.

[29] Rotter J.M. and Teng J.G., Elastic stability of cylindrical shells with weld depressions. J. of Struct. Eng., ASCE, 1989, 115(5), 1244-1263.

[30] Sadowski A.J. and Rotter J.M. A study of buckling in steel silos under eccentric discharge flows of stored solids. J. of Eng. Mech., ASCE, 2010, 136 (6), 769776.

[31] Song C.Y., Effects of patch loads on structural behaviour of circular flat-bottom steel silos. Thin-Walled Structures, 2004, 42, 1519-1542.

[32] Song C.Y. and Teng J.G., Buckling of steel silos subject to code-specified eccentric discharge pressures. Engineering Structures, 2003, 25, 1397-1417.

[33] Sugden M.B., Effect of initial density on flow patterns in circular flat bottomed silos. Proc., Int. Conf. on Design of Silos for Strength and Flow, Univ. of Lancaster, Sep., 1980, 11-28.

[34] Teng J.G. and Song C.Y., Numerical models for nonlinear analysis of elastic shells with eigenmode-affine imperfections. Int. J. of Solids and Structures, 2001, Vol. 38, 3263-3280.

[35] Wood J.G.M., The Analysis of Silo Structures Subject of Eccentric Discharge. Proc. of the $2^{\text {nd }}$ Int. Conf. on Design of Silos for Strength and Flow, Stratfordupon-Avon, 1983, 132-144. 
Published in: Engineering Structures, 33(4), 1187-1194.

DOI: http://dx.doi.org/10.1016/j.engstruct.2010.12.040

[36] Yamaki N., Elastic Stability of Circular Cylindrical Shells, North Holland, Elsevier Applied Science Publishers, Amsterdam, 1984. 